\title{
PROSES PERAWATAN BRAKE PAD MODEL DISK BRAKE
} Ases tamimi ${ }^{1}$ Kemal aditya ${ }^{2}$, Satrio tegar $\mathbf{p}^{3}$,Andi setiawan ${ }^{4}$

\author{
Universitas Muhammadiyah Jember ,Prodi Teknik Mesin
}

\section{A. TUJUAN}

1. Mahasiswa diharapkan dapat memahami prinsip sistem kerja pengereman pada kendaraan roda empat.

2. Mahasiswa dapat mengidentifikasi masalah kerusakan pada disk brake.

3. Sebagai penambah sedikit pengetahuan kepada para pembaca.

\section{B. LANDASAN TEORI}

Memasuki era globalisasi inovasi di bidang otomotif saat ini semakin memanjakan pemakai, dan terobosan teknologi terbaru. Dimasa sekarang kendaraan sudah memakai berbagai sistem yang maju, salah satu dari sistem itu adalah sistem pengereman[1].Pengertian rem atau disk brake secara umum yaitu suatu sistem yang berfungsi untuk menghentikan atau mengurangi laju kecepatan roda pada kendaraan.

Kampas rem sekarang pada umumnya menggunakan material serat komposit alami. Pemanfaatan material komposit pada saat ini semakin berkembang seiring dengan meningkatnya penggunaan bahan tersebut[2]. Masa sekarang kampas rem tidak lagi menggunakan asbestos dikarenakan sudah dilarang untuk dijadikan brake pad atau kampas rem, karena tidak ramah lingkungan dan berdampak mengganggu kesehatan[3].

Dengan cara menginjak pedal rem di bawah kemudi, Pedal Rem juga harus mempunyai gerak bebas yang cukup. Tanpa gerak bebas ini, piston master silinder akan selalu terdorong keluar. Sistem rem menggunakan mekanisme hidrolik yaitu menggunakan Hukum Pascal gaya penampang dari fluida dengan mendistribusikannya melalui pipa kecil menuju piston rem[4], sehingga menciptakan tekanan pada kaliper, agar kampas rem saling bergesekan dengan disc (piringan).

Dengan adanya gesekan antara serat komposit yaitu merupakan kombinasi dua material atau lebih sehingga memberikan sifat yang lebih baik dari material penyusunnya[5] dengan logam ferrous (besi 
cor kelabu, stainless steel) yang dapat menimbulkan panas, Panas rem cakram memiliki efek pengereman yang besar, tetapi luas perpindahan panasnya relatif kecil[6] sehingga mengurangi perputaran roda kendaraan. Pada cara kerja rem cakram gaya gesek yang digunakan untuk mengurangi kecepatan adalah gaya gesek antarakampas rem (brake ped) dengan piringan rem[7].

Disc brake digunakan sebagai pengganti rem tromol, Pada dasarnya piringan cakram, terdiri dari cakram yang berputar dengan rotor dan bahan gesek yang mendorong dan menjepit cakram.

\section{ALAT DAN BAHAN}

Alat dan bahan yang dibutuhkan untuk melakukan perawatan rem cakram/Disk brake pada roda depan:

- Peralatan,

1) 1 Unit kompresor dan spray gun [bila ada]: untuk membersihkan kotoran dan debu dengan udara bertekanan tinggi.

2) Kunci kombinasi pass ring

3) Obeng min [-]

4) Tang Kombinasi

5) Kunci T/Double ring ukuran $12 \mathrm{~mm}$

6) kuas untuk membersihkan debu dan kotoran

7) Sikat kawat / ampelas

8) Minyak tancho atau Grease sebagai Pelumasan bosh bos kaliper

- Bahan

1. Bak penampung komponen/Nampan

2. Kain lap/majun

3. Cairan anti karat

\section{PROSEDUR}

Sebelumnya kita perlu ketahui terlebih dahulu komponen komponen apa saja yang terdapat pada pengereman cakram:

1. Silinder penyetel sepatu rem 
2. Sepatu rem

3. Pegas pembalik

4. Kanvas rem

5. Silinder roda[8]

Berikut adalah prosedur pemeriksaan yang sederhana pada rem kendaraan dengan tipe cakram (brake disc):

1. Lepaskan Roda depan

a) Pertama posisikan kendaraan di tempat permukaan yang sama rata, serta beri penahan pada roda.

b) Lalu lepas penutup roda (jika ada) kendurkan baut pengunci, tapi jangan sampai terlepas dari pelek.

c) Dongkrak mobil dan naikkan as depan kemudian ditahan dengan jack stand pada bagian yang aman di dekat roda yang akan dilepas.

d) Lalu lepaskan semua mur pada roda.

e) Terakhir tarik roda dengan perlahan hingga terlepas [9].

2. Periksa kondisi selang sistem rem

Periksa apakah terdapat retak ataupun kebocoran pada selang rem brake house. Karena Keadaan ini berpotensi merusak seal atau selang minyak rem sehinggarem gagal berfungsi (blong). Yang bisa disebabkan oleh panasnya rem yang juga dapat menurunkan koefisien gesek brake pad secara drastis[10].

3. Periksa kondisi kampas rem

Lepaskan penahan kaliper dan angkat kaliper keatas. lepaskan brake pad atau kampas rem kemudian bersihkan brake pad dengan cairan pembersih kemudian tambahkan grease atau gemuk pada brake pada Disc brake. Jika perlu di ganti, pilih kualitas brake pad yang bagus karena Kejadian rem blong disebabkan oleh kualitas kampas rem yang tidak bagus yang menyebabkan koefisien gesek kampas rem turun signifikan akibat pengaruh kenaikan suhu saat pengereman [11]. 
4. Periksa ketebalan brake pad

Umumnya kampas rem terbuat dari bahan yang bermacam macam. Seperti menggunakan dari bahan :

1) Kampas Rem Non Asbes

2) Kampas Rem Keramik

3) Kampas Rem Metalik[12]

Yang dari ke 3 bahan tersebut memiliki kandungan material yang berbeda - beda. Dalam seiringnya penggunaan kendaraan terus menerus. Maka perlu di perhatikan juga keausan pada kampas rem dikarenakan sering di gunakan otomatis kampas rem mengalami penurunan ketebalan. Dengan Standar ketebalan kampas rem (baru) : 12,05 mm sedangkan Batas servis limit : 11,05 mm Jika batas servis limit melebihi dari $11,05 \mathrm{~mm}$ maka kampas harus diganti dengan yang baru.

5. Periksa kondisi disc brake

Pastikan bahwa tidak ada retakan ataupun kerusakan pada permukaan brake disc. Bersihkan disc brake dengan cairan pembersih dan hilangkan karat pada permukaan disc brake. Jika kondisi fisik disk brake sudah tidak sesuai dengan batas aturan yang di tentukan, artinya ketebalan maupun permukaan tidak sama rata, dapat dilakukan pembubutan.

Mutu yang baik hasil pengerjaan bubut antara lain :

1.Ukuran yang tepat

2.Kehalusan permukaan

3. Geometris hasil bubut

4.Kesuaian terhadap fungsi perakitan[13].

6. Periksa ketebalan disc brake

Ukur ketebalan brake disc dengan mikrometer atau vernier caliper dan pastikan bahwa ketebalannya masih ideal. (Cek nilai standar ketebalan brake disc pada tiap kendaraan). Jika ketebalan brake disc pada tiap titik pengukuran tidak merata maka dapat dilakukan pembubutan, namun apabila ketebalannya berada dibawah batas yang diperbolehkan untuk dilakukan pembubutan, maka brake disc harus diganti. pengukuran disc rotor $18 \mathrm{~mm}$ sampai $17 \mathrm{~mm}$ masih dikatakan baik, Lebih dari itu mungkin perlu untuk di ganti atau di bubut [14]. 
7. Pasang kampas rem

Pasang kembali kampas rem dan kaliper. Kencangkan baut pengunci kaliper dengan nilai torsi yang sesuai.

8. Pasang kembali roda

Pasang roda dan kencangkan baut roda dengan torsi yang sesuai. Pemeriksaan diatas hanya dilakukan pada sistem rem yang menggunakan jenis brake disc (tipe cakram), pada sebagian besar kendaraan.

\section{E. HASIL}

Dari perawatan rutin sistem rem, menghasilkan kenyamanan berkendara dan keawetan pada part lain. Dikarenakan bila terjadi sedikit saja masalah pada rem dapat langsung di analisis dan di perbaiki ke bengkel.

Serta terdapat tips atau cara untuk melakukan pengereman yang benar agar rem tidak mudah rusak yaitu, Jika mobil sudah di lengkapi dengan sistem ABS (Anti lock braking system) yang dimana sebuah inovasi baru untuk menjaga keselamatan dengan cara kerja rem sendiri bila ketika menginjak pedal rem maka secara otomatis rem mobil akan melakukan sistem teknik kocok. Sedangkan bila mobil belum di lengkapi sistem ABS maka perlu dilakukan teknik kocok dengan secara bergantian ketika menurunkan kecepatan mobil dengan menginjak dan melepas pedal rem mobil secara bergantian dalam waktu cepat, menyesuaikan dengan kecepatan mobil.

\section{F. KESIMPULAN}

Disk brake sendiri dapat kita tarik kesimpulan bahwa di dalam sistem rem mempunyai beberapa part atau komponen lainya seperti kampas rem, piringan rem (Disk brake), selang rem serta kaliper dan banyak lagi. Dengan itu kita harus melakukan pengecekan secara berkala. Karena peran rem dalam kendaraan sangat penting untuk melakukan pengurangan laju kendaraan ketika dalam keadaan yang dibutuhkan, karena jika rem tidak berfungsi ataupun mengalami rem blong maka akan berakibat sangat fatal bagi pengendara maupun orang lain. Oleh karena itu "Sistem rem di mobil juga sangat dianjurkan dilakukan perawatan berkala, minimal setiap 20.000 kilometer," papar Ignatius Nova Risdianto, Kepala mekanik bengkel Andala Auto Service di Jl. Radio Dalam Raya, Gandaria Utara, Jakarta Selatan. 


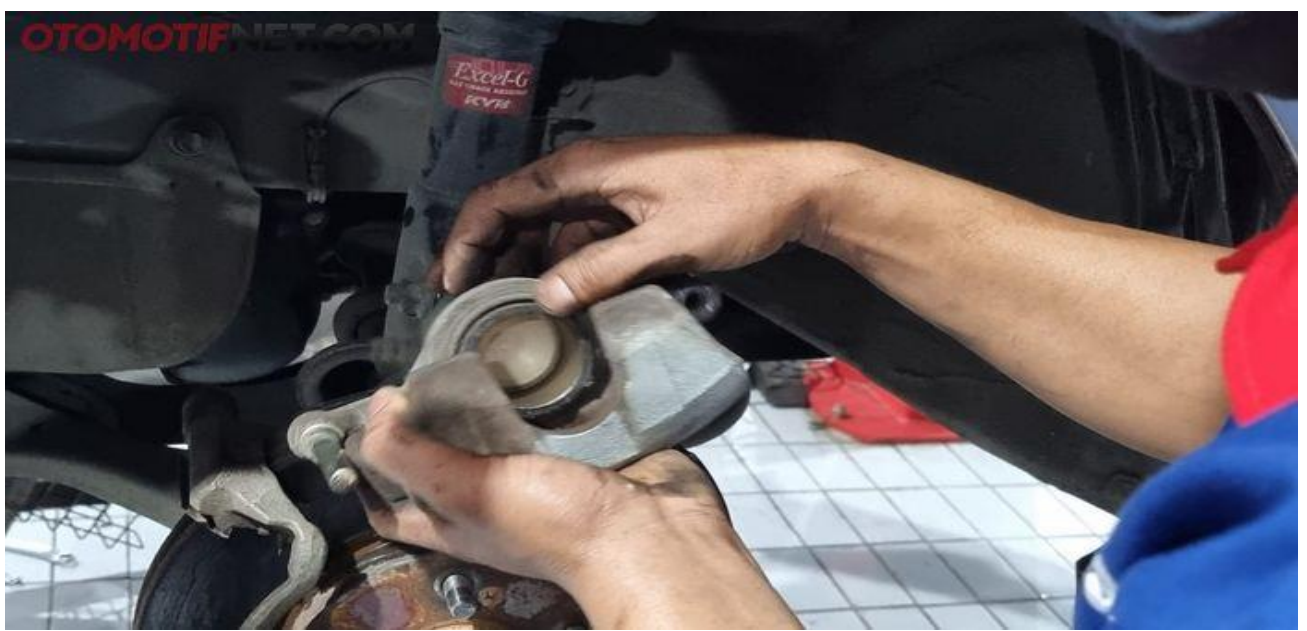

[15] Gambar 1 Ilustrasi pengecekan kaliper rem dari kemungkinan adanya kebocoran dan kotoran

\section{G. DAFTAR PUSTAKA}

[1] S. Diki, S. B. St, I. Melya, D. Sebayang, and S. Si, "PRINSIP KERJA REM DISC BRAKE DAN PERAWATANNYA."

[2] "3 jp".

[3] “J-Proteksion: Jurnal Kajian Ilmiah dan Teknologi Teknik Mesin", [Online]. Available: http://jurnal.unmuhjember.ac.id/index.php/J-Proteksion

[4] D. Listyadi, C. Ghozali, S. Pengajar, J. T. Mesin, F. Teknik, and U. Jember, "KARAKTERISTIK ALIRAN FLUIDA PADA LENGKUNGAN S (DUA ELBOW 90) DENGAN VARIASI JARAK ANTARA ELBOW DAN ARAH KELUARAN."

[5] A. A. Rosyadi and J. T. Mesin, "PENGARUH KADAR PARTIKEL ADITIF MONTMORILLONITE TERHADAP SIFAT MEKANIK SIKLUS TERMAL KOMPOSIT POLYESTER SERAT KAYU KOPI."

[6] A. Sukandi, K. Anggi Prayoga, and K. Rasyid, "Modeling dan Simulasi Transient Thermal pada Rem Cakram Sepeda Motor." [Online]. Available: http://jurnal.pnj.ac.id

[7] A. N. Akhmadi, "PENGARUH PENGEREMAN TERHADAP KECEPATAN MOBIL LISTRIK TUXUCI 2.0 DENGAN REM CAKRAM DOUBEL PISTON," vol. 4, 2015.

[8] "TINJAUAN PUSTAKA 2.1. Sistem pengereman."

[9] B. A. Proyek Pengembangan Kuri Kulum Di Rektorat Pendi Di Kan Menengah Kejuruan Di Rektorat Jenderal Pendi Di Kan Dasar Dan Menengah and K. Modul, "MELEPAS, MEMASANG DAN MENYETEL RODA BI DANG KEAHLI AN TEKNI K MESI N PROGRAM KEAHLI AN TEKNI K MEKANI K OTOMOTI F."

[10] A. L. A. Sjarip and A. Suhadi, "Analisis Desain Disc Brake Rotor Pada Kendaraan Roda Empat." 
[11] M. B. Prakoso, D. Tryono Siregar, and A. S. Siregar, "ANALISA BRAKE SHOE MOBIL AVANZA VELOZ 1,5 TOYOTA AKIBAT SISTEM PENGEREMAN."

[12] M. Mushlih Elhafid, D. Djoko Susilo, and P. Joko Widodo, "Pengaruh bahan kampas rem terhadap respon getaran pada sistem rem cakram," 2017.

[13] K. Kunci, K. pemakanan, and geometrik poros, "PENGARUH KEDALAMAN PEMAKANAN TERHADAP KEBULATAN GEOMETRIK POROS HASIL BUBUT," 2018.

[14] J. Teknik, M. Politeknik, and N. Bali, "ANALISIS GANGGUAN SISTEM REM PADA MOBIL DAIHATSU XENIA SERTA PENANGANANNYA I Nengah Ludra Antara," 2018.

[15] “kaliper-rem-juga-wajib-diperiksa-20210618112315". 